\title{
KLARINET ÜFLEME YÖNTEMINDE KARŞILAŞILAN PROBLEMLER VE ÇÖZÜMLERi
}

\section{Elif SINDIR*}

\section{ÖZET}

Dünya ülkelerinde ve ülkemizde klarinet üfleme teknikleri çeşitlilikler göstermektedir. Bu çeşitlilik, Avrupa'da klarinetin tarihsel gelişimi boyunca ortaya çıkan ve benimsenen çalma ekollerinin farklılığından kaynaklanmaktadır. Bu tekniklerin yanlış uygulanması klarinet yorumcularının birtakım problemlerle karşılaşmasına neden olabilmektedir. Bu çalışmada, kullanılan üfleme pozisyonları ve bunların ortak özelliklerine dayanarak doğru üfleme yöntemine nasıl ulaşılması gerektiği amaçlanmıştır. Buna ek olarak klarinet yorumcularının üfleme metodunu nasıl oluşturduğu, ton üretiminde karşılaştıkları problemler, bu problemlerin nedenleri ve bunlara getirilen çözümler ele alınmıştır.

Anahtar Kelimeler: Klarinet Üfleme Yöntemi, Üfleme Tekniği, Çalma Ekolü, Üfleme Pozisyonu, Ton Üretimi.

* Eskişehir Büyükşehir Belediyesi Senfoni Orkestrası, Eskişehir / TÜRKIYE, esindir29@gmail.com 


\section{PROBLEMS ENCOUNTERED IN CLARINET EMBOUCHURE AND THEIR SOLUTIONS}

\section{Elif SINDIR*}

\section{ABSTRACT}

Techniques of blowing the clarinet vary in our country and other countries in the world. This variety stems from the diversity in the playing schools, which appeared and were adopted in Europe during the historical development of the clarinet. The misapplication of these techniques may cause some problems for the clarinet performers. This study aims to explain how to reach at the right embouchure based on the playing positions and their common characteristics. In addition to this, how clarinet performers develop the embouchure; problems that they encounter in producing tone; reasons for these problems and solutions proposed for them have been explored.

Key Words: Embouchure, Blowing Technic, Playing School, Blowing Position, Tone Production. 


\section{GíRIŞ}

Klarinet yorumcuları, klarinetten doğru ve kulağa hitap eden sesi elde etmek amacıyla özel bir üfleme tekniği kullanmaktadır. Bu üfleme tekniği dünyada "embouchure” olarak adland1rılmaktadır. Fransızca "la bouche" (ağız) sözcügüunden türeyen bu terim, çalgı üfleme yöntemi anlamına gelmektedir (Brymer, 1976:123). Dudakların ve onu çevreleyen yüz kas-larının ağızlığın etrafında, diyaframın da yardımı ile bir basınç yaratarak enstrümanın içine hava gönderme tekniğidir. Klarinetin tarihsel gelişimi süresince klarinet ve klarinet materyal-leri bir evrim süreci geçirmiş ve yorumcular bu sürece fiziksel olarak uyum sağlamak zorunda kalmıştır. Örneğin modern klarinetlerdeki uygulamanın aksine, 18. yüzyılda, klarinetin atası olan “chalumeau”da kamış, üfleme yerinin ön kısmına yerleştirilmiştir (Pino,1980: 194). Yo-rumcu buna göre obua ve fagotta olduğu gibi çift dudak üfleme yöntemini kullanmıştır. Bu üfleme yöntemi, 1820 'de üfleme yerinin değişimiyle 21. yüzylla kadar kullanılmaya devam etmiştir. Çift dudak yönteminin pürüzsüz bir ton üretemediğini savunan Carl Baermann (1810-1885), tek dudak üfleme yöntemini kullanan ilk klarinet ustası olmuştur (Gerber, 2015). 21. yüzyılda da dünyanın çeşitli bölgelerinde bu yöntemi kullananlar bulunmaktadır. Üfleme kısmının yorumcunun dudak hizasına yerleştirilmesinden sonra, tek dudak yöntemi kul-lanılmaya başlanmıştır. Bu metodda, üst dudak serbest ancak alt dişler alt dudağ 21. yüzyılda klarinet eğitiminde ve yorumculuğunda dünyada en çok kullanılan üfleme yöntemi bu olmuştur.

Klarinette üfleme yöntemi, dudakların ve çalgıyı üfleyebilmek için gereken yanak kaslarının çalgıya diyafram kasının da desteğiyle hava akışını sağlayan üfleme tekniğidir. Ağız boşluğunun boyutu, dudak kaslarındaki gerilim ya da gevşeklik, dilin pozisyonu ve işlevi, diyaframdan gelen havayı doğru bir şekilde çalgıya göndermek, klarinet tonu üretmede önemli rol oynayan faktörlerdir. Üfleme metodu doğru ise çalgının çalan kişiye verdiği tepki başarılı olmaktadır. Üfleme yöntemi birtakım hatalar içeriyorsa çalgının tonu, kontrolü ve entonasyonu (ses kararlılı̆̆ı) sorunlu olabilmektedir.

\subsection{KLARİNETTE ÜFLEME YÖNTEMINIIN ÇEŞITTLERİ}

\section{a. Tek Dudak Üfleme Yöntemi}

Tek dudak üfleme metodunda alt dudak alt dişleri örtmektedir. Üst dişler ise direk olarak ağızlı̆̆ın üst kısmına yerleştirilmektedir. Bu çalışma tek dudak üfleme yöntemi baz alınarak yapılmıştır.

\section{b. Çift Dudak Üfleme Yöntemi}

Bu üfleme metodunda, alt dişler ve alt dudak tek dudak yöntemiyle aynı işlevi gör-mekte, buna ek olarak üst dişler direk olarak ağızlığa değil üst dudak tarafından kapatılarak ağızlıkla üst dişler arasına sıkıştırılmaktadır. Çift dudak üfleme yöntemi acı verici ve kondisyon açısından uzun süre sürdürülemeyen bir süreç olduğundan dolayı, dünyada çoğunlukla klarinetçiler arasında tek dudak üfleme yöntemi tercih edilmektedir. 


\section{2. ÜFLEME POZİSYONU OLUŞTURULMASI}

a. Klarinetin baril ve ağızlık kısmı birleştirilir.

b. Dudaklar sağlam bir şekilde kapatılır, çene aşağı ve ileri doğru hareket ettirilir.

c. Öndeki üst ve alt dişler yatay ve dikey, bunun yanında aralarında $1 \mathrm{~cm}$. mesafe olacak şekilde aynı hizada olmalıdır.

d. Bu pozisyonda ağız kapalı, alt dudak alt dişleri örtecek şekilde kıvrılmalıdır. Bu noktada dudağın ne kadar kıvrılması gerektiği büyük önem teşkil etmektedir. Alt dudak çizgisinden itibaren alt dudağın alt dişleri kapatması doğru bir üfleme pozisyonu için yeterli olmaktadır (Pino, 1969: 54).

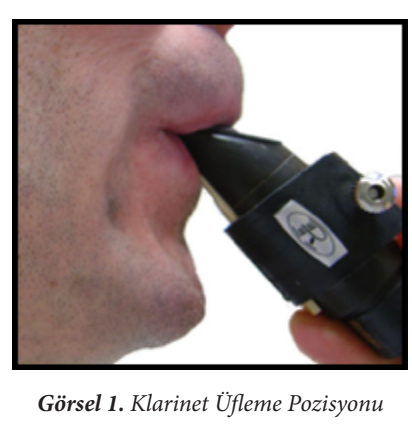

e. Klarinet üflerken alt dişleri örten alt dudak bir çemberin alt yarısını oluşturduğunu düşünerek, kamış ve ağızlığın birleştiği noktaya denk gelecek şekilde ağızlı̆̆a dayanmalıdır (Gerber, 2010). Dudaklarda hissedilen dikey bir oval şekil olmalı ve alt dişler alt dudağa kenetlenmiş olmalıdır (Pino, 1980: 62).

f. Kapalı olan ağıza baril ve ağızlık yukarıda belirtildiği gibi, aynı zamanda vücuda 35-40 derece açı verecek şekilde ve üst dişleri de ağızlı̆̆ın uç kısmına temas edecek şekilde yerleştirilmelidir. Bu noktada ön alt ve ön üst dişlerin birbirine paralel olmasına özen gösterilmelidir.

\section{3. ÜFLEME YÖNTEMINNIN VE TON ÜRETIMININ OLUŞTURULMASI}

Klarinette ton üretiminin oluşmasını sağlarken sadece dudak pozisyonu değil, bunun yanında diyafram da hava akışını kesintisiz bir şekilde dudağa gönderen ve ton üretimini ortaya çıkmasını sağlayan en önemli etkendir. Diyafram kasının doğru kullanılması etkileyici ve güzel tona sahip olmak açısından önem taşımaktadır.

a. Dudakların kenarlarından nefes alındıktan sonra bel çevresini genişletecek şekilde nefes alınır.

b. Dudakların kenarları ağızlığı çevreleyecek şekilde nefes alınır.

c. Ağızlığın içine nefes verilir ancak bunu yaparken sıkı bir şekilde genişlemiş olan bel çevresinin içindeki hava, dudak pozisyonu ve esnetilmiş boğaz ve dil kasının pozisyonu korunmaya özen gösterilir. Diyafram kası ile desteklenmiş hava akışı eşit ve düzenli bir şekilde damaktan 
ağız boşluğuna ve ağızlığa gönderilir (Pino; 1980: 131 ).

d. Hava akışının temposu aşamalı olarak arttırılır. Tempo yükseldikçe kamış titreşime uğrayacak ve ton üretilecektir.

\subsection{TON ÜRETIMINII SAĞLAYAN ETKENLER}

Çift dudak ve tek dudak üfleme pozisyonunun kontrolünde, dudağın yerleştirilmesine ek olarak ton üretimini etkileyen 3 faktör bulunmaktadır (Brymer; 1976: 55).

a. Çene kasları: Sadece kamışa yapılan baskıyı değil yatay yönde tınlamayı sağlayan oyuntunun ölçüsünü dilin hareketi ile yükselterek ya da alçaltarak isteğe göre ayarlamaktır.

b. Yanak kasları: Ağızın oyuntusuna göre şekillenmektedir. Dudakların kontrolünü sağlaması açısından sabit olmalıdır. Diyaframdan gelen basınç sırasında hava kolonunu içermesi gerekmektedir.

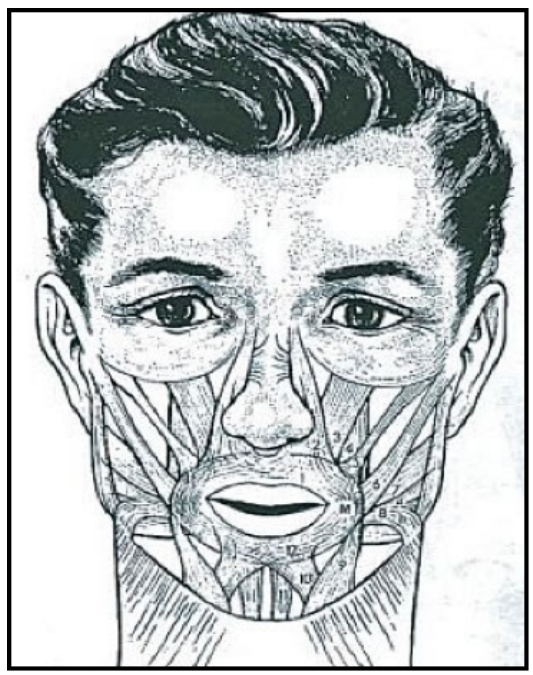

Görsel 2. Dudak ve Yanak Kasları

c. Dil: Bir kas yapısı olan dil de ton üretiminde gerekli olan diğer kaslarla aynı ölçüde gerilim ve gevşeme oranına sahiptir (Brymer, 1969: 58). Kamış aracılığıyla sese girişi hazırlar ve staccato (sesleri kesintili olarak tane tane çalış) çeşitlerini üretir.

\section{YÖNTEM}

Bu çalışmada, 25 yıllık bir çalıcılık deneyiminin sonucunda, yanlış üfleme tekniği ile klarinet çalmanın zorlukları ve sonuçları ortaya konmuş, bu yanlışların nasıl düzeltileceği açıklanmıştır. $\mathrm{Bu}$ doğrultuda, güzel ton üreten, doğru üfleme yönteminin nasıl oluşturulması gerektiği örneklerle betimlenmiştir. 


\section{1 Üfleme Yönteminde Karşılaşılan Problemler}

a. Klarinet üfleme yönteminde en göze çarpan sorunlardan bir tanesi alt dudak ve alt çene ilişkisidir. Bu noktada önemli olan alt dudağın ne ölçüde kıvrılması gerektiğidir. Bunun doğruluğunu test etmek için işaret parmağını alt dudağa bastırmak ve dişlerin temas ettiği yerden itibaren alt dişleri alt dudakla örtmektir (Campione, 1999). Bunun sonucunda çene düz bir pozisyon almalıdır. Klarinete yeni başlayan öğrencilerde alt çenede kasların güçsüzlüğü sebebiyle çenede gamzeli bir pozisyon olabilmektedir. Ayna karşısında uzun ses çalışması bu soruna çözüm getirmektedir. Bu yöntem dudakların köşelerinden hava kaçırılmasının da önemli oranda kontrol altına alınmasını sağlamaktadır (Gerber, 2010).

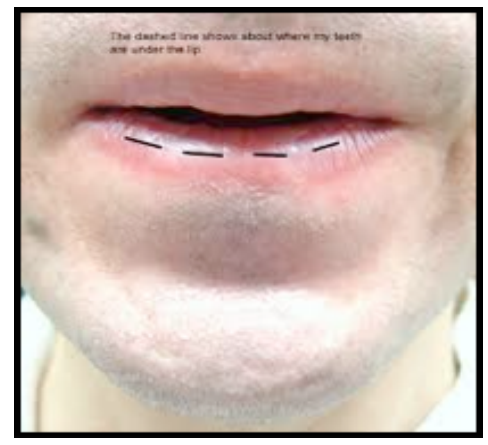

Görsel 3. Doğru bir üfleme pozisyonunda alt dudağın çeneye yerleştirilme noktası

b. Alt dudağın gereğinden fazla dişlerin üzerini kaplaması üfleme metodu problemlerinden bir tanesidir. Bu durumda çene yüze oranla daha altta kalır ve perdeli, küçük bir ton üretilmiş olur. Tiz sesler daha metalik tınlamakta, bunun yanında üfleme esnasında çalgıdan kulağa hoş gelmeyen birtakım sesler çıkmasına neden olmaktadır (Campione, 1999). "Staccato" veya sese giriş kamışa direkt olarak değil, dudak aracıllğıyla elde edilmektedir. Bu da "staccato"nun net tınlamamasına neden olmaktadır. Üfleme pozisyonunda düz bir çene elde etmek amacıyla çoğu zaman çalıcılar bu yanlışa düşebilmektedir.

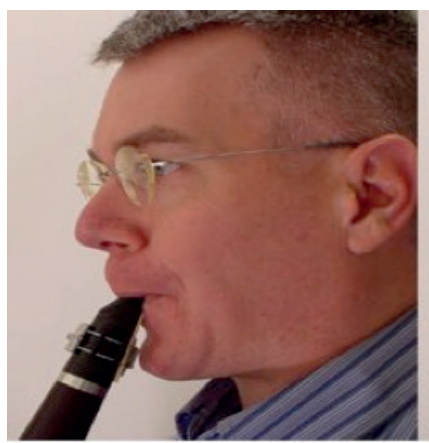

Correct: flat chin, cheeks are firm to direct air into mouthpiece.

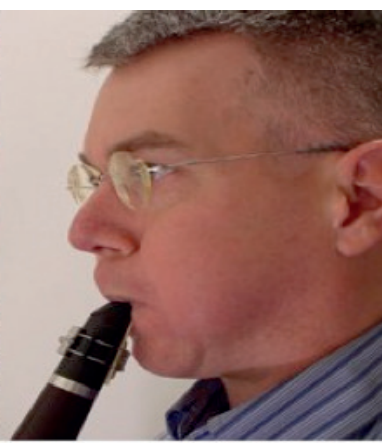

Incorrect: Puffy cheeks and so8 8 y chin

Görsel 4. Doğru ve yanlış klarinet üfleme pozisyonu 
Diğer taraftan alt alt dudağın alt dişleri yeteri kadar kapatamaması ise üflerken rahatsız edici bir hisse neden olmakta ve bu üfleme pozisyonunda da kontrol edilemeyen sesler oluşmasının önüne geçilememektedir.

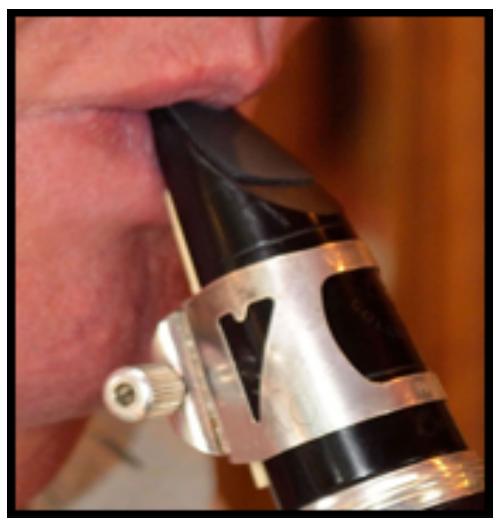

Görsel 5. Alt dudă̆ın serbest birakılması

c. 20.yy’a kadar klarinet üflenirken dudakları "e" şeklinde düşünmek, bu dönemin klarinetçileri arasında çok kullanılan bir üfleme metodu olmuştur. Tersine gülerek çalmak ve dudaklarda "e" şeklinin oluştuğunu düşünmek tonu olumsuz yönde etkileyebilmektedir. Bunun yanında, "e" pozisyonuyla büyük bağlı aralıklar üflenirken, bağın bölünmüş bir şekilde tınladığı gözlenmektedir (Campione, 1999).

d. Klarinet çalıcılarının karşılaştığı ortak sorunlardan biri, doğası gereği alışkın olduğu 1sırma davranışını çalgıyı üflerken de sergilemektir. Ancak bu, kamışın titreşimini azalttığından dolayı ton esnekliğinin de eksilmesine yol açmaktadır. Çift dudak üfleme yöntemini bir süreliğine kullanmak bu sorunun önüne geçerek tonda olumlu anlamda bir rahatlama sağlamaktadır (Gerber 2010).

e. Çalgıyı üflerken dudakların köşelerinin geriliminin ve baskısının dinamik çeşitlilik içerisinde değişmememesi gerekmektedir. Bu durum kasların güçsüz olduğu anlamına gelmektedir. Kas gücünü geliştirmek amacıyla uzun ses çalışması yapılmalıdır. Uzun sesler tiz çalgı aralığında "forte" (kuvvetli) dinamiğinde başlamalı ve pes çalgı aralığında "decrescendo" (sesi gittikçe söndürerek) dinamiği ile söndürülmelidir (Gerber 2010).

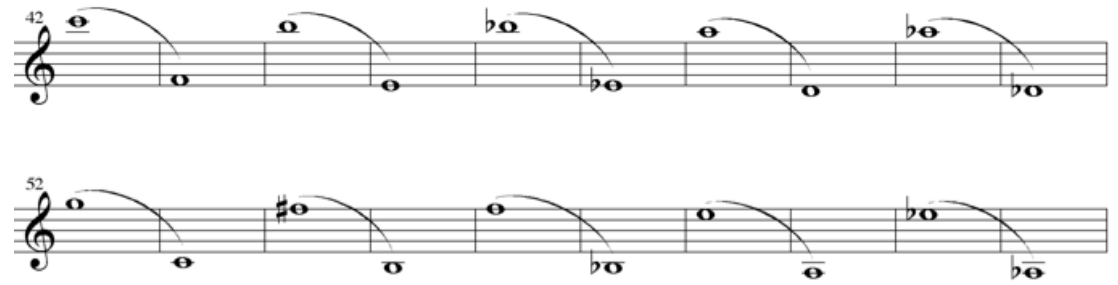

Şekil 1. Tiz çalgı aralığından başlayan 12'li uzun ses çalışması 
Diğer bir çalışma ise oktav ve onikili aralıkların "piano" (hafif) dinamiğinden itibaren "crescendo" (sesi gittikçe kuvvetlendirerek) yapılması, tiz notalarda dudak köşelerinden ve diyaframdan daha fazla basınç uygulamaktır. Bu şekilde üflenirken dudak basıncının doğru noktada olmasını sağlamak için başparmak desteği ile çalgı ağızdan içeriye doğru itilmeli ve "a" ve "o" gibi vokal pozisyonlarla destek verilmelidir (Gerber, 2010).

f. Üfleme pozisyonu doğru entonasyonu (ses kararlılığı) yakalamak açısından da oldukça önemlidir. Pozisyon fazla esnek ise çalgının pesleşmesine neden olmaktadır. Alt çene ile üfleme pozisyonuna verilen basınç tizleşmeyi kolaylaştırmaktadır. Bağlı notaların önce "forte", sonra "piano" ve tersi şekilde çalınması bu problemin çözümünde yardımcı olmaktadır. Eğer çalgı tizleşirse çeneyi geri çekmek ve diyaframdan fazladan hava göndermek bu problemin çözümünde önemli rol oynamaktadır. Bu çalışma yapılırken entonasyon cihazı kullanmak önemlidir.

g. Üfleme yönteminde dilin pozisyonu gerektiğinde kamışa 1 saniyenin altında bir süre içerisinde dokunacak ve staccato üretecek şekilde geride durmalıdır. Dilin fazla geride dur-ması, hem dilin hem de üfleme için gerekli organların da gerilmesine yol açabilmektedir. (Brymer 1969) Yanaklar tarafından oluşturulan kas çeperi, damak, ön dişler, dil altı, titreşen kamış geniş bir ağız boşluğuyla çevrelenmelidir. Bu da yine "a" ve "o" gibi vokal pozisyonları kullanarak ve üfleme pozisyonunu dikey oval bir şekilde düşünerek mümkün olabilmektedir.

h. Dudak kenarlarından hava kaçırılması da klarinetçilerin karşılaştığı problemlerden bir tanesidir. Bu dudak ve yanak kaslarının yorgun olmasından kaynaklanmaktadır. Bunu engellemek için ayna karşısında ikinci oktav sol sesini üflemek ve boştaki sol elin parmakları ile hava kaçırılan bölgeye basınç uygulayarak çalışmak yeterli olabilmektedir. Bazen dudaklardan çıan hava sesi klarinetçiler tarafından tercih edilen bir ses olabilmektedir. 


\section{SONUÇ}

Bütün bu verdiğimiz bilgilerin ışığında dünyada farklı klarinet üfleme pozisyonlarıyla çalındığı gözlenmektedir. Her pozisyonun kendine göre zorlukları ve kolaylıkları olabilmek-tedir. Zorlukların birtakım çalışma ve alıştırmalarla üstesinden gelinebilmektedir. Çalıcı kendine uygun ve doğal olan pozisyonu zaman içinde bulacak ve oturtacaktır (Gerber, 2010). Yukarıda da belirtildiği gibi alt çene ve alt dudak ilişkisi bu noktada çok büyük bir önem teşkil etmektedir. Örneğin; alt dişleri örtmek için gereğinden fazla alt dudak kullanıldığında ve belli bir süre geçtikten sonra bu yöntem değiştirildiğinde, bu değiştirme dönemi çalıcı için zorlu bir süreç olabilmektedir. Bu durumda dudak ve yanak kasları klarinete yeni başlayan bir çalıcının kasları gibi işlev görecektir. Dudak ve yanak kaslarında performans sırasında yorulma meydana gelerek, çalıcının seyirci karşısında oldukça zor anlar yaşamasına yol açacaktır. Bunun yanında değişitirilen üfleme metoduyla, bu kasların farklı şekilde işlev görmesi sonucunda, "staccato" kalitesi değişmektedir. Sekizlik ve daha uzun değerdeki noktalı notaları kısa çalmak mümkün olamamamaktadır (Ör: Mozart'ın Klarinet Konçertosunun ilk cümlesi) .

Bu problemin çözüm aşamasında öncelikle çalıcının eğitmeninin, çalıcının üfleme metodundaki yanlışları mümkün olduğunca erken farkına varması ve derhal bu duruma müdahale etmesi gerekmektedir. Bu duruma ne kadar erken müdahale edilirse çalıcıya bir o kadar zaman kazandırılmış olur. Aksi takdirde, belli bir üfleme yöntemi oluşturulduktan ve kasların gelişimi bu yönde oturtulduktan sonra farklı bir pozisyon ile çalınması dudak ve yanak kaslarında uzun süre çok güç onarılacak bir deformasyon meydana getirebilmektedir. Çalıcının dudak kaslarının toparlanması süre olarak 10 yılı bulabilmektedir. Bu süreci atlatmak için öncelikle kararlı ve sabırlı olunmalıdır. Buna ek olarak birtakım çalışmalar bu süreci kolay atlatmaya yardımcı olabilmektedir.

a. Yeni üfleme yönteminin dayanıklılığını arttırmak amacıyla uzun ses alıştırmaları yapılabilir. En pes notadan beşli, oktav ve onikili aralıkları farklı dinamiklerle üflemek dudak ve yanak kaslarının direncini arttırmaktadır.

b. Gam, arpej, üçlü ve oktav çalışmalarının hiç bağ olmadan sadece "detache" (dil vurarak çalma) ya da "staccato" olarak çalınması dudak ve yanak kaslarını güçlendirmektedir.

c. Duo ve trio gibi oda müziği gruplarında yer almak çalma kondisyonunu artırarak bu problemin ortadan kaldırılmasına bir nebze de olsa yardımcı olmaktadır.

d. Mümkün olduğunca çok etüt çalışmak ve bunları durmadan çalmak yorumcunun kondisyonunun dayanıklılı̆̆ını artırmaktadır. 


\section{KAYNAKÇA}

Brymer, Jack. (1969/2008) Clarinet, İngiltere: Yehudi Menuhin Music Guides.

Hoeprich, Eric. (2008) The Clarinet, Norfolk: Yale University Press.

Pino, David. (1980) The Clarinet and Clarinet Playing, New York: Dover Publications.

Harris, Paul. (1995) Teaching the Clarinet, The Cambridge Companion to the Clarinet, Camb-ridge: Cambridge University Press.

https://tr.scribd.com/document/158119916/, Campione, Carmine. The Clarinet Embou-chure

(Erişim Tarihi: 15.07.2016)

https://tr.scribd.com/document/57084683, Gerber, Allison. Problems and Solutions Re-garding Clarinet Embouchure (Erişim Tarihi: 17.07.2016)

http://www.musicaseria.com, Krein Reed, Mihael. The Secret of Developing a Clarinet Em-bouchure (Erişim Tarihi: 21.07.2016)

https://mramusicplace.net/, McLane, Ralph. Double Lip Embouchure and the Clarinet

(Erişim Tarihi:23.07.2016)

Görsel1. http://test.woodwind.org/clarinet/BBoard/read.html? f=1ぬi=173869ঊt=173869 (Erişim Tarihi: 07.08.2016)

Görsel2.http://test.woodwind.org/http://www.theclarinet.co.uk/articles/why-does-air-escape-from-the-sides-of-mymouth/ (Erişim Tarihi: 11.08.2016)

Görsel 3. http://www.clarinet-now.com/ (Erişim Tarihi: 12.08.2016)

Görsel 4. http://www.clarinet-now.com/images/clarinet-embouchure-side-strawberry-chin.jpg, (Erişim Tarihi: 12.08.2016)

Görsel 5. http://www.lesliecraven.co.uk/ (Erişim Tarihi: 12.08.2016)

Şekil 1. http://www.mrobinsonmusic.com/long-tones.htm (Erişim tarihi:18.08.2016) 